\title{
405 W Erbium-Doped Large-Core Fiber Laser
}

\author{
Huaiqin Lin, Yujun Feng, Pranabesh Barua, Jayanta K. Sahu, and Johan Nilsson* \\ Optoelectronics Research Centre, University of Southampton, Southampton SO17 1BJ, UK \\ *jn@orc.soton.ac.uk
}

\begin{abstract}
An Yb-free Er-doped fiber laser with a 146- $\mu \mathrm{m}$ diameter core produces a recordbreaking output power of $405 \mathrm{~W}$ at $1.6 \mu \mathrm{m}$ with a slope efficiency of $37 \%$ when cladding-pumped at $977 \mathrm{~nm}$.

OCIS codes: (060.2410) Fibers, erbium; (140.3480) Lasers, diode-pumped; (140.3510) Lasers, fiber
\end{abstract}

\section{Introduction}

In recent years, significant progress has been achieved in the power scaling of $\mathrm{Yb}$-doped fiber lasers operating at 1.0 $-1.1 \mu \mathrm{m}$ [1]. Owing to spectroscopic differences between Er and $\mathrm{Yb}$ ions, the power of Er-doped fiber lasers (EDFLs), which emit at $1.5-1.6 \mu \mathrm{m}$, has lagged far behind that of Yb-doped fiber lasers. One issue is erbium's small absorption cross-section, which makes it to use cores with low V-value and thus achieve a good beam quality. Nevertheless, there is great interest in high-power Er-doped fiber lasers due to their relative eye-safety and the atmospheric transparency in the $1.5-1.6 \mu \mathrm{m}$ wavelength range [2]. They are also attractive for pumping midinfrared laser sources, e.g., supercontinuum sources. In some cases, the beam-quality requirements are modest, e.g., for pumping of Tm-doped fiber lasers emitting at $\sim 2 \mu \mathrm{m}$.

Efforts on the optimization of Er-doped fiber lasers have led to a series of impressive results. One approach is the use of $\mathrm{Yb}$ co-doping, to overcome the low absorption of Er. Er-Yb co-doped fibers are pumped in the $0.9-1 \mu \mathrm{m}$ wavelength range and have been scaled to $297 \mathrm{~W}$ of output power [3], which is the highest power reported to date. However, the onset of parasitic Yb-lasing at $1-1.1 \mu \mathrm{m}$ as well as a high thermal load are obstacles for further power-scaling. High-efficiency in-band cladding-pumping of Er-doped fibers with $1535 \mathrm{~nm}$ Er:Yb co-doped fiber lasers (EYDFLs) is an alternative approach. This way, a maximum output power of $264 \mathrm{~W}$ was obtained [4]. Although the 264-W laser also was co-doped with $\mathrm{Yb}$, this played no part in the laser cycle. Consequently, the approach has also been used with Yb-free EDFLs, pumped by 1535-nm EYDFLs as well as by 1480-nm fiber Raman lasers. However this use of so-called tandem-pumping, in which a fiber laser is pumped by one or several other fiber-lasers, significantly increases the cost, size and complexity of the system.

Cladding-pumping of $\mathrm{Yb}$-free Er-doped fiber lasers directly with diodes is an alternative to this. This approach has been pursued with 1.5- $\mu \mathrm{m}$ pump diodes, which offers a low thermal load in the EDFL as one of its attractions. Unfortunately, however, multimode $1.5-\mu \mathrm{m}$ pump diodes lag behind their $0.9-1-\mu \mathrm{m}$ counterparts in power as well as efficiency. Thus, the highest output power of $88 \mathrm{~W}$ from an EDFL pumped in-band by diodes was limited by the available diode laser power at $1.53 \mu \mathrm{m}$ [5]. In comparison, a continuous-wave Er fiber laser core-pumped by a highpower, $1480 \mathrm{~nm}$ Raman fiber laser generated over $100 \mathrm{~W}$ of output power [6]. Furthermore, despite the high opticalto-optical efficiencies that can be achieved with in-band pumping, the overall efficiency suffers from the low efficiency of the pump sources. As a result, the overall electrical-to-optical efficiency may well be below 15\% [7].

Alternatively, it is also possible to cladding-pump Yb-free EDFLs with more potent diode lasers at $0.98 \mu \mathrm{m}$. This approach was investigated in the 1990's by Minelly et al. [8], and has since then been power-scaled to $103 \mathrm{~W}$ of output power [9]. Though the large quantum defect increases the thermal load, the superb brightness, efficiency, and cost of $0.98-\mu \mathrm{m}$ diodes are clear advantages of this approach.

In this paper, we present a record-power Yb-free Er-doped fiber laser cladding-pumped at $0.98 \mu \mathrm{m}$. We used a simple end-pumped fiber laser configuration, and were able to generate $405 \mathrm{~W}$ of output power centered at $1603 \mathrm{~nm}$ with $37 \%$ slope efficiency for $1140 \mathrm{~W}$ of launched pump power. The fiber core diameter of $146 \mu \mathrm{m}$ and length of $36 \mathrm{~m}$ were chosen to provide adequate pump absorption and distribution of the thermal load. The output power was limited by self-pulsation, which caused catastrophic damage to the fiber facet.

\section{Experimental setup}

An Er-doped fiber was designed and fabricated in-house by the standard modified chemical-vapor deposition (MCVD) and solution doping technique. The inner cladding was D-shaped with short diameter of $660 \mu \mathrm{m}$ and long diameter of $700 \mu \mathrm{m}$. These parameters were chosen to match the pump beam quality $\left(\mathrm{M}^{2}\right.$-value $\left.~ 350-400\right)$ and provide good pump overlap with the core. The $\mathrm{Er}^{3+}$-doped aluminosilicate core had a diameter of $146 \mu \mathrm{m}$ and a numerical aperture (NA) of 0.08 ( $\mathrm{V}=22.9$ at the signal wavelength of $1603 \mathrm{~nm})$. The fiber was coated with a lowrefractive index polymer which provided a nominal inner-cladding NA of 0.48 . The small-signal absorption in the 
inner cladding was $\sim 0.6 \mathrm{~dB} / \mathrm{m}$ at the pump wavelength of $979 \mathrm{~nm}$. From this we estimate an $\mathrm{Er}^{3+}$-concentration of 4200 ppm by weight.

The experimental laser configuration is depicted in Fig. 1. To obtain sufficient pump absorption, we used a 36-m long piece of the fiber. Even so, the pump absorption was low, which we attribute to the D-shaping of only 5.7\%. Therefore, we coiled the fiber into a figure-eight shape to scramble the modes and thus improve the pump absorption to $\sim 11 \mathrm{~dB}$. We used three 1.1-kW diode-laser-stack-based sources centered at $977 \mathrm{~nm}$ to pump the fiber through both of its ends, via a combination of lenses and dichroic mirrors. In one end of the fiber, two of the pump sources were spatially beam-combined into one beam. We obtained launch efficiencies of $~ 73 \%$ in the beam-combined end and $\sim 87 \%$ in the other. Both ends of the fiber were polished perpendicularly to the fiber axis, without any further processing. At the end of the laser cavity with a single pump source, high-reflectivity feedback was provided by a pair of dichroic mirrors having high transmission at the pump wavelength and high reflection at the signal wavelength. The laser output coupler was formed by the 4\%-reflecting facet at the other end of the fiber. The signal was separated from the pump beam using another dichroic mirror having the same characteristics as the feedback mirror. Both fiber ends were held in temperature-controlled metallic size-matched V-grooves designed to prevent possible thermal damage to the fiber coating by any non-guided pump or signal power, or by the heat generated in the laser cycle. For further heatsinking, the fiber was coiled on metal cylinders and air-cooled by fans.

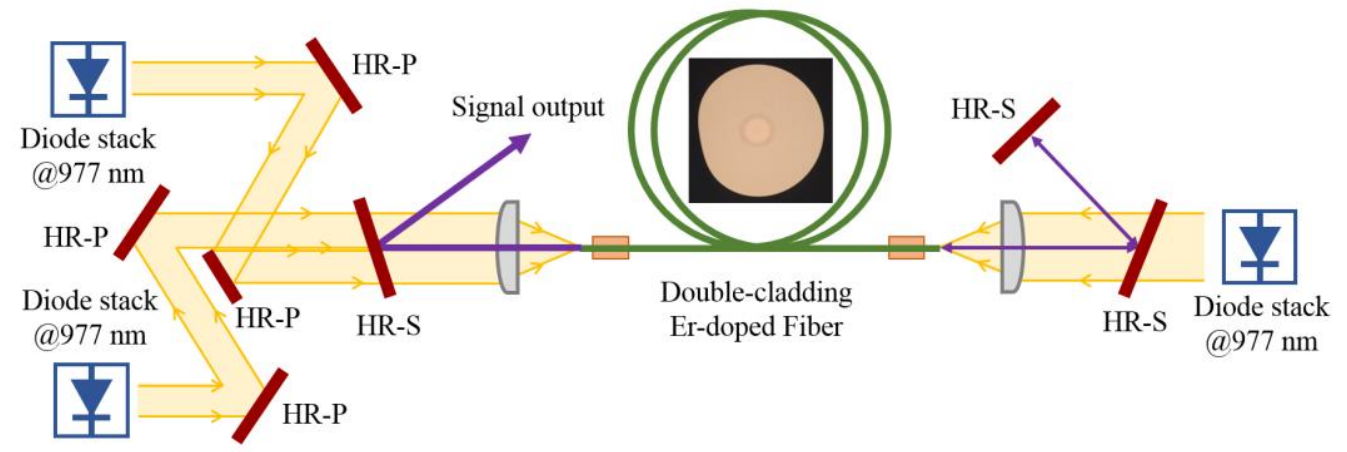

Fig. 1. Schematic of the Er-doped fiber laser system. HR-P: high reflectivity at pump wavelength, HR-S: high reflectivity at signal wavelength

\section{Results}

The laser output power as a function of the launched pump power is shown in Fig. 2(a). The maximum output power was $405 \mathrm{~W}$ with a corresponding optical-to-optical conversion efficiency of $39 \%$, if the pump leakage of $8 \%$ is discounted. The laser output power increased linearly with the launched pump power and showed no evidence of roll-off even at the highest output power. The laser slope efficiency was $37 \%$ with respect to the launched pump power. This is significantly lower than the $53 \%$ achieved when a 2 -m-long piece of the fiber was core-pumped at $976 \mathrm{~nm}$. The core-pumped laser emitted at $1558 \mathrm{~nm}$, and we attribute the improved efficiency to reductions in excited-state absorption and / or background losses. The output spectrum measured at the maximum output power of the cladding-pumped laser is plotted in Fig. 2(b). The spectrum was centered at $1603.5 \mathrm{~nm}$ and had a 3-dB linewidth of approximately $5.6 \mathrm{~nm}$.
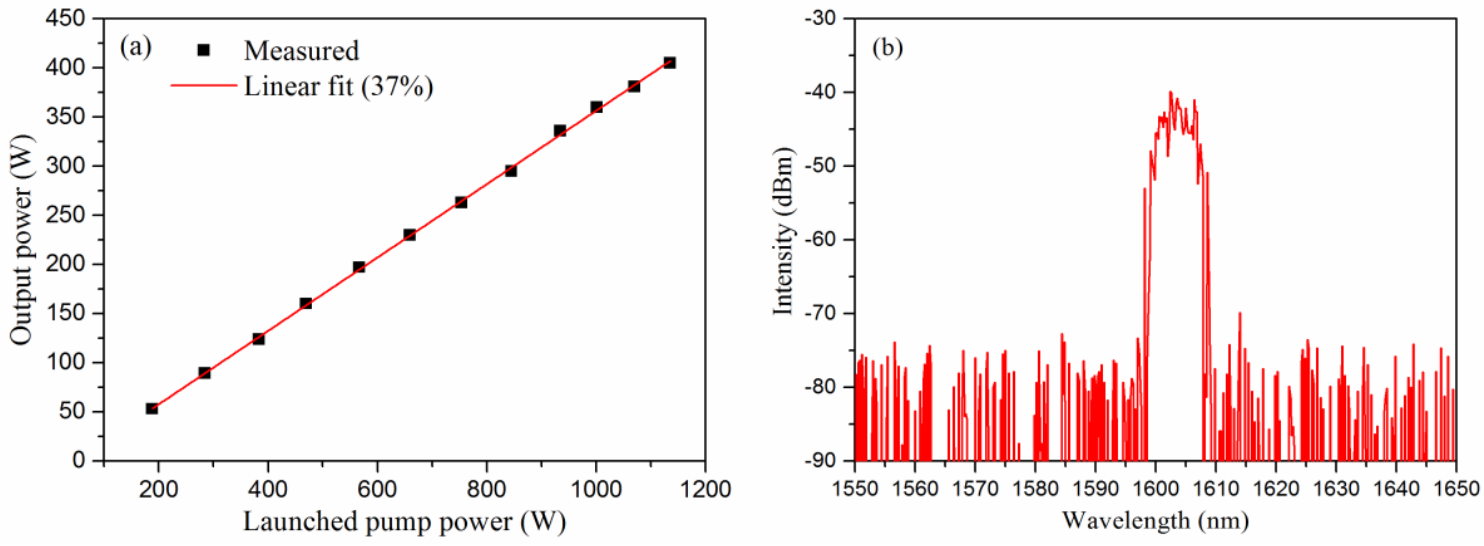

Fig. 2. (a) Laser output power versus launched pump power, (b) Laser output spectrum at $405 \mathrm{~W}$ output. Resolution: $1 \mathrm{~nm}$. 
Fiber-end failure prevented power-scaling beyond $406 \mathrm{~W}$. The large quantum defect and comparatively low efficiency makes thermal damage of the low-index polymer outer cladding (maximum durable temperature well below $200^{\circ} \mathrm{C}$ ) a critical issue, especially at the fiber ends. In our case, the average heat dissipation was as low as $18 \mathrm{~W} / \mathrm{m}$ with a $36 \mathrm{~m}$ long fiber, and no thermal degradation of the coating was observed. Pulsing is also a potential failure mechanism. The temporal-power characteristic was monitored using a $460-\mathrm{kHz}$ photodetector and a $20-\mathrm{GHz}$ oscilloscope. A series of intense pulses at irregular intervals were observed, as shown in Fig. 3(a). These self-pulses are attributed to sustained relaxation oscillations, which can be caused by clustered erbium ions [10]. Fig. 3(b) shows one transient oscillation of the self-pulses with an oscillation frequency of $\sim 50 \mathrm{kHz}$. The inset shows an individual pulse with a duration of $20 \mathrm{~ns}$ measured by a $12-\mathrm{GHz}$ photodetector. We believe that these high-energy, high-peak-power pulses caused catastrophic fiber-facet damage. Investigations of failed ends supported this view. We believe that this fiber is capable of producing higher output powers if the self-pulsing is suppressed and possibly even scale to the maximum launched pump power, which we estimate to $1.9 \mathrm{~kW}$ with the pump diodes we used.
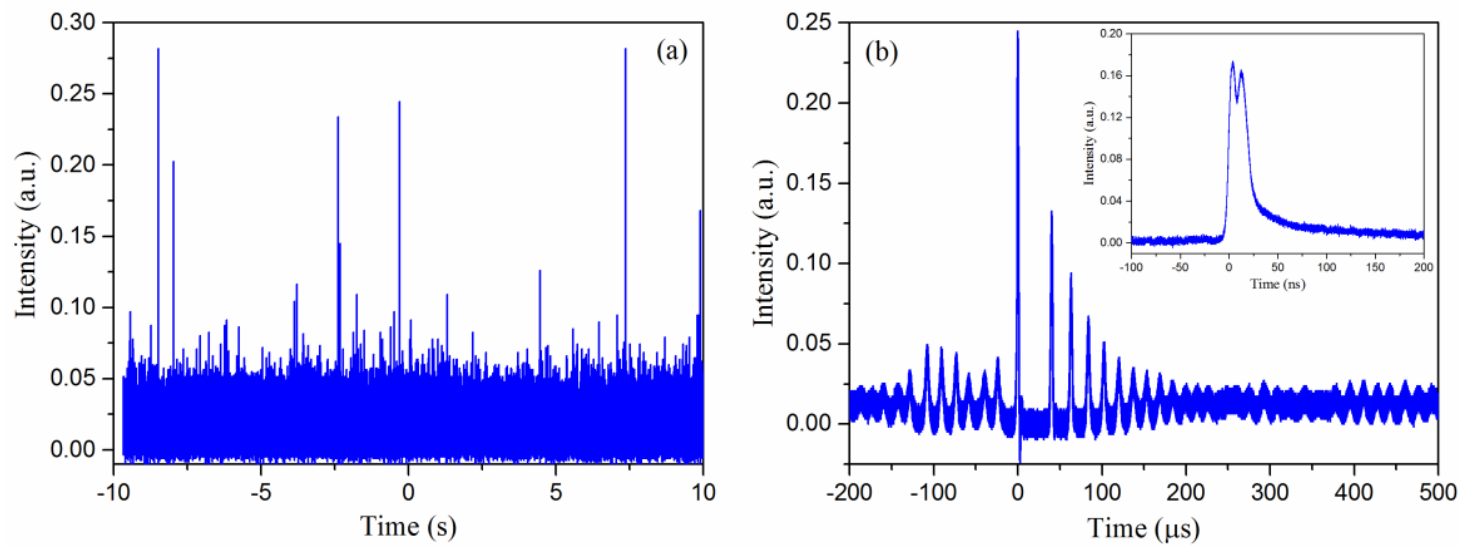

Fig. 3. (a) High-intensity irregular-frequency self-pulses from the Er-doped fiber laser at an output power of $200 \mathrm{~W}$, (b) One transient oscillation of the self-pulses. Inset: the temporal trace of an individual self-pulse.

\section{Conclusion}

We have demonstrated a directly diode-pumped high-power fiber laser emitting in the eye-safe wavelength range. The laser is based on an $\mathrm{Yb}$-free Er-doped large-core double-cladding fiber fabricated using the conventional MCVD and solution doping process. The fiber laser is capable of producing output with a record power level from any Er-doped fiber laser, i.e., $405 \mathrm{~W}$ at $1603 \mathrm{~nm}$. The slope efficiency was $37 \%$ with respect to the launched pump power. Further power scaling is expected by suppressing catastrophic self-pulsation at high pump powers. Although the beam quality was not measured, it is bound to be poor but is still expected to be sufficient for pumping of Tmdoped fiber lasers.

This work was funded by EPSRC (EP/P001254/1) and AFOSR (FA9550-14-1-0382).

\section{References}

[1] D. J. Richardson, J. Nilsson, and W. A. Clarkson, "High power fiber lasers: current status and future perspectives [Invited], J. Opt. Soc. Am. B 27, 63-92 (2010).

[2] V. R. Supradeepa, J. W. Nicholson, "Power scaling of high-efficiency $1.5 \mu \mathrm{m}$ cascaded Raman fiber lasers," Opt. Lett. 38, $2538-2541$ (2013)

[3] Y. Jeong, S. Yoo, C. A. Codemard, J. Nilsson, J. K. Sahu, D. N. Payne, R. Horley, P. W. Turner, L. Hickey, A. Harker, M. Lovelady, and A. Piper, "Erbium:ytterbium co-doped large-core fiber laser with 297 W continuous-wave output power," IEEE J. Sel. Top. Quantum Electron. 13, 573-579 (2007).

[4] M. A. Jebali, J. N. Maran, and S. LaRochelle, " $264 \mathrm{~W}$ output power at $1585 \mathrm{~nm}$ in Er-Yb codoped fiber laser using in-band pumping," Opt. Lett. 39, 3974-3977 (2014).

[5] J. Zhang, V. Fromzel, and M. Dubinskii, "Resonantly cladding-pumped Yb-free Er-doped LMA fiber laser with record high power and efficiency," Opt. Express 19, 5574-5578 (2011).

[6] V. R. Supradeepa, J. W. Nicholson and K. Feder, "Continuous wave erbium-doped fiber laser with output power of $>100 \mathrm{~W}$ at $1550 \mathrm{~nm}$ inband core-pumped by a $1480 \mathrm{~nm}$ Raman fiber laser," in Conference on Lasers and Electro-Optics (CLEO), 2012, paper CM2N.8.

[7] M. A. Jebali, J. Maran, S. LaRochelle, S. Chatigny, M. Lapointe, and E. Gagnon, "A 103W High Efficiency In-Band Cladding-Pumped 1593 nm All-Fiber Erbium-Doped Fiber Laser," in Conference on Lasers and Electro-Optics (CLEO), 2012, paper JTh1I.

[8] J. D. Minelly, Z. J. Chen, R. I. Laming, and J. E. Caplen, "Efficient Cladding Pumping of an Er ${ }^{3+}$ Fibre," in 21st European Conference on Optical Communication (ECOC), 1995, pp. 917-920

[9] L. V. Kotov, M. E. Likhachev, M. M. Bubnov, O. I. Medvedkov, M. V. Yashkov, A. N. Guryanov, S. Fevrier, J. Lhermite, and E. Cormier, "Yb-free Er-doped all-fiber amplifier cladding-pumped at $976 \mathrm{~nm}$ with output power in excess of $100 \mathrm{~W}$ ", in Proceedings of SPIE, Fiber Lasers XI: Technology, Systems, and Applications, 2014, paper 89610X.

[10] P. Le Boudec, M. Le Flohic, P. L. Francois, F. Sanchez, and G. Stephan, "Influence of ion pairs on the dynamical behaviour of $\mathrm{Er}^{3+}$-doped fibre lasers," Opt. Quantum Electron. 25, 501-507 (1993). 